\title{
KẾT QUẢ ĐIỀU TRỊ UNG THƯ NộI MẠC TỬ CUNG TÁI PHÁT BẰNG PHÁC Đồ PACLITAXEL CARBOPLATN VÀ MộT SỐ YẾU TỐ ẢNH HƯởNG
}

\section{TÓM TẮT}

Mục tiêu: Nhận xét kết quả điều trị ung thư nội mạc tử cung tái phát bằng phác đồ paclitaxel carboplatin và một số yếu tố ảnh hưởng đến kết quả điêuu trị. Đối tượng và phương pháp: Nghiên cứu hồi cứu kết hợp tiến cứu trên 54 bệnh nhân ung thư nội mạc tử cung tái phát, tại bệnh viên K. Kết quả: Đáp ứng chung $75,9 \%$ trong đó đáp ứng hoàn toàn $31,5 \%$; đáp ứng một phần 44,4\%, bệnh giữ nguyên $11,1 \%$ và $13 \%$ bệnh tiến triển. Trung vị thời gian sống thêm bệnh không tiến triển là 6 tháng. Trung vị thời gian sống thêm bệnh không tiến triển nhóm chưa từng điều trị hóa chất cao hơn nhóm đã từng điều trị hóa chất (10 tháng so với 6 tháng, $p=0,041$ ). Kết luâan: Phác đồ phối hợp Paclitaxel Carboplatin có hiệu quả trên bệnh nhân ung thư nối mạc tử cung tái phát. Nhóm chưa điều trị hóa chất có gian sống thêm bệnh không tiến triển dài hơn nhóm đã từng điều trị hóa chất.

Tư khóa: Ung thư nội mạc tử cung tái phát

\section{SUMMARY \\ EVALUATING RESULTS OF PACLITAXEL CARBOPLATIN IN THE TREATMENT OF RECURRENT ENDOMETRIAL CANCER, IN K HOSPITAL}

Objectives: Evaluation of Overall Response Rate and Progression Free Survival in patients with recurrent endometrial cancer treated with paclitaxel carboplatin. Materials and methods: A retrospective and prospective descriptive study was conducted on 54 recurrent endometrial cancer patients received Paclitaxel Carboplatin in K hospital. Results: The overall response rate was 75,9\%; complete response was $31,5 \%$; partial response account $44,4 \%$. Stable disease was recorded as $11,1 \%, 13 \%$ of patients disease progresses. Median of progression free survival was 6 month. Conclusions: Paclitaxel carboplatin regimen is effective in recurrent endometrial cancer patients.

Key words: Recurrent endometrial cancer patients

\section{I. ĐẶT VẤN ĐỀ}

Ung thư nội mạc tử cung (UTNMTC) là bệnh lý khối u ác tính phát sinh từ lớp nội mac tử cung. Tại Mỹ, ung thư nội mạc tử cung phổ biến thứ 4 ở nữ chỉ đứng sau ung thư vú, ung thư phổi, ung thư đại trực tràng. Ung thư nội mạc tử

*Bệnh viện K cơ sở Tân Triều

Chịu trách nhiệm chính: Khúc Chí Hiếu

Email: oncohieu@gmail.com

Ngày nhận bài: 19.8.2021

Ngày phản biện khoa học: 19.10.2021

Ngày duyệt bài: 27.10.2021

\section{Khúc Chí Hiếu*, Phùng Thị Huyền*}

cung có tiên lượng tốt so với ung thư buồng trứng và ung thư cổ tử cung. Bệnh thường tái phát trong 3 năm đầu kể từ thời điểm chẩn đoán[1],[2],[3]. Vị trí tái phát của bệnh rất đa dạng, có thể tái phát ở âm đạo, tiểu khung, trong ổ bụng hoặc di căn xa đển các cơ quan khác. Tiên lượng bệnh khi tái phát phụ thuộc vào nhiều yếu tố như vị trí tái phát, thời gian tái phát,... Một số phác đồ hóa chất sử dụng trong điều trị bước một ung thư nội mạc từ cung tái phát là: Paclitaxel phối hợp Carboplatin (TC), doxorubicin phối hợp cisplatin (AP) hay phác đồ kết hợp ba thuốc Doxorubicin, Cisplatin và Paclitaxel (TAP). Tại bệnh viện $K$, phác đồ đầu tay điều trị ung thư nội mạc tử cung tái phát là Paclitaxel phối hợp Carboplatin. Tôi thực hiện đề tài: "Kết quả điều trị ung thư nội mạc tử cung tái phát bằng phác đồ Paclitaxel Carboplatin và một số yếu tố ảnh hưởng kêt quả"với mục tiêu: Nhận xét kêt quả điều trị ung thư nội mạc tử cung tái phát bằng phác đồ Paclitaxel Carboplatin và một số yếu tố ảnh hưởng đến kết quả điêu trị.

\section{II. ĐỐl TƯỢNG VÀ PHƯƠNG PHÁP NGHIÊN CỨU}

2.1. Đối tượng nghiên cứu. Nghiên cứu trên 54 bệnh nhân UTNMTC tái phát được điều trị phác đồ Paclitaxel Carboplatin bước 1 tại bệnh viện $K$ từ tháng $1 / 2016$ đến tháng $5 / 2021$.

2.2. Phương pháp nghiên cứu. Phương pháp nghiên cứu mô tả hồi cứu kết hợp tiến cứu.

Cõ mẫu thuận tiện, chúng tôi thu thập được 54 bệnh nhân

2.3. Phác đồ điều trị. Hóa chất phối hợp Paclitaxel Carboplatin được sử dụng trong điều trị ung thư nội mạc tử cung tái phát. Liều dùng Paclitaxel $175 \mathrm{mg} / \mathrm{m} 2$ Carboplatin AUC 5-7 ngày 1 chu kỳ 21 ngày.

\section{KẾT QUẢ NGHIÊN CỨU}

Bảng 1. Đặc điểm lâm sàng và cận lâm sàng chẩn đoán ban đâu

\begin{tabular}{|c|c|c|c|}
\hline \multicolumn{2}{|c|}{ Đặc điểm } & $\begin{array}{c}\text { Số bệ̂nh } \\
\text { nhẩn }\end{array}$ & $\begin{array}{c}\text { Tỉ lệ } \\
\text { (\%) }\end{array}$ \\
\hline \multicolumn{2}{|c|}{ Tuối trung bình ( \pm SD) } & \multicolumn{2}{|c|}{$56,9 \pm 7,6$} \\
\hline \multirow{2}{*}{ PS } & 0 & 51 & 94,4 \\
\cline { 2 - 4 } & 1 & 3 & 5,6 \\
\hline \multirow{2}{*}{$\begin{array}{c}\text { Mô bệnh } \\
\text { học }\end{array}$} & $\begin{array}{c}\text { Carcinoma dạng } \\
\text { nội mạc }\end{array}$ & 47 & 87 \\
\cline { 2 - 4 } & Khác & 7 & 13 \\
\hline
\end{tabular}


VIETNAM MEDICAL JOURNAL N² - NOVEMBER - 2021

\begin{tabular}{|c|c|c|c|}
\hline \multirow{3}{*}{ ER } & Dương tính & 18 & 33,3 \\
\cline { 2 - 4 } & Ám tính & 8 & 14,8 \\
\cline { 2 - 4 } & Không rõ & 28 & 51,9 \\
\hline \multirow{3}{*}{ PR } & Dương tính & 14 & 25,9 \\
\cline { 2 - 4 } & Âm tính & 12 & 22,2 \\
\cline { 2 - 4 } & Không rõ & 28 & 51,9 \\
\hline \multirow{3}{*}{ CA 125 } & Cao & 20 & 37,1 \\
\cline { 2 - 4 } & Bình thường & 24 & 44,4 \\
\cline { 2 - 4 } & Không rõ & 10 & 18,5 \\
\hline \multirow{2}{*}{$\begin{array}{c}\text { Điều trị } \\
\text { hóa chất }\end{array}$} & Có & 43 & 79,6 \\
\cline { 2 - 4 } & Không & 11 & 20,4 \\
\hline
\end{tabular}

Nhân xét: Tuối trung bình trong nghiên cứu này là 56,9 , chủ yếu các bệnh nhân có PS 0 . Có 47 bệnh nhân trong nghiên cứu typ mô bệnh học là carcinoma dạng nội mạc (chiếm 87\%). 28 bệnh nhân không rõ tình trạng thụ thể nội tiết (chiếm 51,9\%). Tỉ lệ bệnh nhân CA125 ở mức cao là $37,1 \%$.

Bảng 2. Đặc điểm di căn

\begin{tabular}{|c|c|c|}
\hline Vị trí di căn & Số bệnh nhân & Tỉ lệ (\%) \\
\hline Gan & 15 & 27,8 \\
\hline Phối & 10 & 18,5 \\
\hline ố bụng & 25 & 46,3 \\
\hline Xướng & 9 & 16,7 \\
\hline Hạch ngoại vi & 10 & 18,5 \\
\hline Mỏm cụt & 13 & 24,1 \\
\hline Khác & 6 & 11,1 \\
\hline
\end{tabular}

Nhận xét: Trong nghiên cứu các vị trí tái phát thường gặp là ổ bụng, gan, mỏm cụt chiếm tỷ lệ tương ứng là 46,3\%,27,8\%,24,1\%. Một số vị trí ít gặp hơn là phổi và hạch ngoại vi chiếm $18,5 \%$, xương chiếm $16,7 \%$.

Bảng 3. Số vị trí di căn

\begin{tabular}{|c|c|c|}
\hline Số vị trí di cắn & Số BN & $\mathbf{\%}$ \\
\hline 1 & 39 & 72,2 \\
\hline 2 & 13 & 24,1 \\
\hline 3 & 2 & 3,7 \\
\hline
\end{tabular}

Nhận xét: Tại thời điểm chẩn đoán tái phát có 39 trường hợp có 1 vị trí di căn, 13 trường hợp 2 vị trí di căn và 2 trường hợp có 3 vị trí di căn.

Bảng 4. Số chu kỳ điều trị

\begin{tabular}{|c|c|}
\hline Số chu kỳ điều trị & Chu kỳ \\
\hline Tổng số chu kỳ & 305 \\
\hline Trung bình & 5,6 \\
\hline Giá trị nhỏ nhất & 3 \\
\hline Giá trị lớn nhất & 9 \\
\hline
\end{tabular}

Nhận xét: Tống số chu kỳ điêu trị là 305, Số chu kỳ trung bình: 5,6; Bệnh nhân điều trị ít nhất 3 chu kỳ, bệnh nhân điều trị nhiều nhất 9 chu kỳ, tại thời điểm kết thúc nghiên cứu không có bệnh nhân nào đang tiếp tục điều trị.

Bảng 5. Đáp ứng điều trị

\begin{tabular}{|c|c|c|}
\hline Đáp ứng & (n) & $\mathbf{\%}$ \\
\hline Hoàn toàn & 17 & 31,5 \\
\hline
\end{tabular}

\begin{tabular}{|c|c|c|}
\hline Một phần & 24 & 44,4 \\
\hline Bệnh giữ nguyên & 6 & 11,1 \\
\hline Tiến triễn & 7 & 13,0 \\
\hline Tống & $\mathbf{5 4}$ & $\mathbf{1 0 0}$ \\
\hline
\end{tabular}

Nhân xét: Có 17 bệnh nhân đáp ứng hoàn toàn $(31,5 \%) 24$ bệnh nhân đáp ứng một phần $(44,4 \%)$. Có 6 bệnh nhân chiếm $11,1 \%$ bệnh giữ nguyên, 7 bệnh nhân bệnh tiến triển (13\%), tỷ lệ kiểm soát bệnh (bao gồm đáp ứng hoàn toàn, đáp ứng một phần và bệnh giữ nguyên) là $87 \%$.

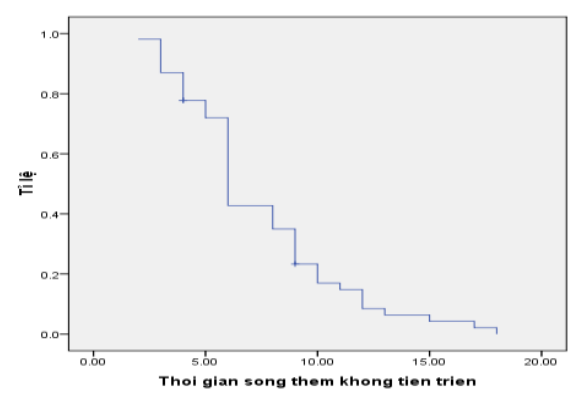

\section{Biểu đồ 1. Thời gian sông thêm bệnh không tiến triên}

Nhân xét: Trung vị thời gian sống thêm bệnh không tiến triển 6 tháng (CI 95\%: 5,5-6,5).

Biểu đồ 2. Thời gian sống thêm bệnh không tiến triển theo dạng mô bệnh học

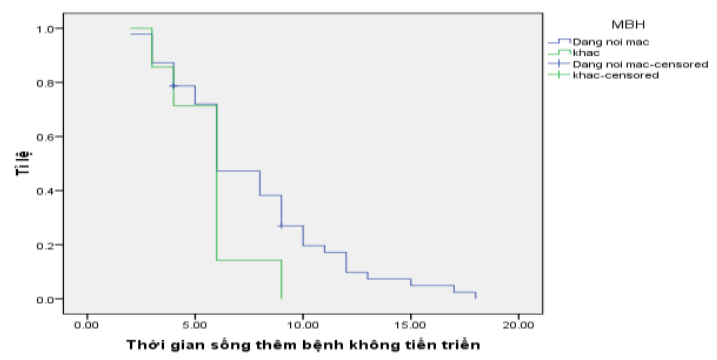

Nhận xét: Trung vị thời gian sống thêm bệnh không tiến triển của nhóm có mô bệnh học dạng nội mạc tử cung và mô bệnh học khác là 6 tháng với $p=0,145$

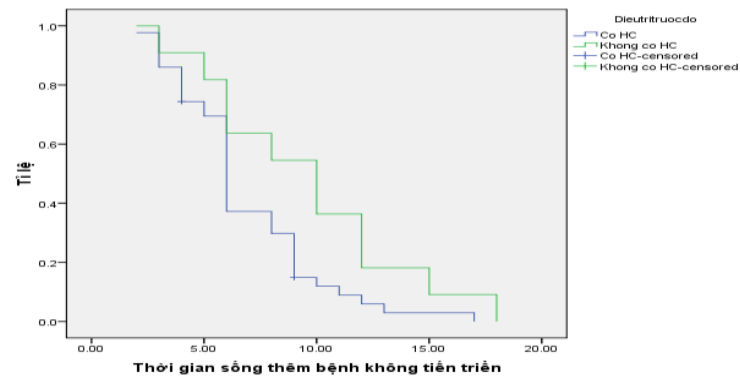

Biểu đồ 3. Thời gian sống thêm bệnh không tiến triển theo tiền sử dùng hóa chất 
Nhận xét: Trung vị thời gian sống thêm bệnh không tiến triển của nhóm trước đó từng điều trị hóa chất là 6 tháng, của nhóm chưa từng điều trị hóa chất trước đó là 10 tháng. Sự khác biệt có ý nghĩa thống kê với $p=0,041$.

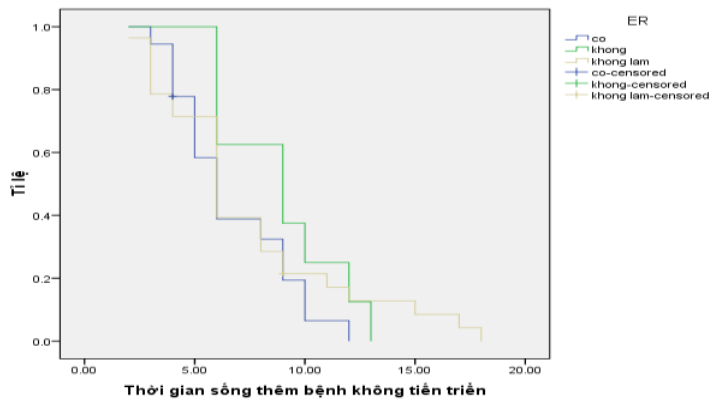

Biểu đồ 4. Thời gian sống thêm theo tình trang ER

Nhân xét: Trung vị thời gian sống thêm bệnh không tiến triển của nhóm ER dương tính là 6 tháng, nhóm $E R$ âm tính là 9 tháng và của nhóm không rõ tình trạng ER là 6 tháng. Sự khác biệt không có ý nghĩa thống kê với $p=0,4$.

\section{BÀN LUÂ̂N}

Trong nghiên cứu của chúng tôi, tuổi trung bình của đối tượng nghiên cứu là 56,9 tuổi. Bệnh nhân trẻ tuổi nhất trong nghiên cứu là 33 tuổi, cao nhất là 77 tuổi. Kết quả này tương tự với kết quả nghiên cứu của Đặng Tiến Giang và cộng sự (cS) thực hiện năm 2020 với độ tuổi trung bình 56,6 tuổi. Các vị trí tái phát hay gặp nhất là ổ bụng, gan, mỏm cụt chiếm tỷ lệ tương ứng là $46,3 \%, 27,8 \%, 24,1 \%$. Kết quả này phù hợp với đặc điểm sinh học giai đoạn tái phát di căn của UTNMTC[3].

Tổng số chu kỳ điều trị trong nghiên cứu của chúng tôi là 305 , số chu kỳ trung bình 5,6. Bệnh nhân được điều trị ít nhất 3 chu kỳ, bệnh nhân được điều trị nhiều nhất 9 chu kỳ, tại thời điểm kết thúc nghiên cứu không có bệnh nhân nào đang tiếp tục điều trị. Số chu kỳ điểu trị gián tiếp phản ánh thời gian sống thêm bệnh không tiến triển, như vậy với kết quả nghiên cứu số chu kỳ điều trị có thể dự đoán được phác đồ này giúp kéo dài đáng kể thời gian sống thêm không tiến triển.

Kết quả nghiên cứu của chúng tôi có 17 bệnh nhân đáp ứng hoàn toàn $(31,5 \%) 24$ bệnh nhân đáp ứng một phần $(44,4 \%)$, có 6 bệnh nhân chiếm $11,1 \%$ bênh giữ nguyên, 7 bểnh nhân bệnh tiến triển (13\%), tỷ lệ đáp ứng chung (bao gồm đáp ứng hoàn toàn và đáp ứng một phần) là $75,9 \%$. Kết quả này cao hơn so với kết quá nghiên cứu của $\mathrm{D}$ Pectasides và cs có tỉ lệ đáp ứng chung là $62 \%$. Sự chênh lệch này có thể do sự khác biệt về đặc điểm đối tượng nghiên cứu. Tỉ lệ đáp ứng cao so với các phác đồ khác như Lyposomal Doxorubicin là lý do phác đồ Paclitaxel Carboplatin được lựa chọn đầu tay trong điêu trị bước 1 UTNMTC tái phát[4],[5].

Đối với giai đoạn tái phát di căn, kéo dài thời gian sống thêm bệnh không tiến triển là mục tiêu chính của các phác đồ điêu trị. Trong nghiển cứu của chúng tôi, trung vị thời gian sông thêm bệnh không tiến triển là 6 tháng (CI 95\%: 5,5$6,5)$. Một nghiên cứu tương tự với nghiên cứu chúng tổi là nghiên cứu GOG 0209, trung vị thời gian sống thêm bệnh không tiến triển của nhóm điều trị phác đồ paclitaxel carboplatin là 13 tháng. Kết quả này cao hơn của chúng tôi vì đối tượng nghiên cứu trong GOG 0209 bao gồm cả người bệnh ở giai đoạn 3 và 4 còn nghiên cứu của chúng tôi chỉ gồm những bệnh nhân ở giai đoạn tái phát di căn[6].

Một nghiên cứu hồi cứu được thực hiện bởi A.N.J. Huijgens và cs thu thập bệnh nhân từ 2002 đến 2010 nhằm đánh giá những yếu tố dự báo tái phát UTNMTC cho thấy thể mô bệnh học, độ mô học, tình trạng nội tiết có liên quan đến tăng tỉ lệ phát sau điêu trị của UTNMTC[7],[8]. Chúng tổi cho rằng các yếu tố tương tự có thể ảnh hưởng đến tiên lượng UTNMTC tái phát cũng như ảnh hưởng đến kết quả điều trị. Khi phân tích dưới nhóm, kết quả cho thấy tiền sử trước đó được điều trị hóa chất có ảnh hưởng đến thời gian sống thêm bệnh không tiến triển của phác đồ. Nhóm có điều trị hóa chất trước đó (bao gồm những trường hợp đã được điều trị hóa chất trong giai đoạn bổ trợ bằng bất kì phác đồ nào) có trung vị thời gian sống thêm bệnh không tiến triển thấp hơn nhóm chưa từng điều trị hóa chất ( 6 tháng so với 10 tháng với $p=0,041$ ). Kết quả này gợi ý cho chúng ta liệu có xảy ra sự kháng thuốc đối với những trường hợp trước đó đã từng điều trị hóa chất hay không vì nhóm từng được điều trị hóa chất trước phần lớn đã được điều trị bằng phác đồ Paclitaxel Carboplatin trong giai đoạn điều trị bổ trợ. Những yếu tố khác như tình trạng nội tiết, thể mô bệnh học không liên quan đến thời gian sống thêm bệnh không tiến triển (sự khác biệt không có ý nghĩa thống kê).

\section{KẾT LUÂN}

- Đáp ứng chung 75,9\% trong đó đáp ứng hoàn toàn $31,5 \%$; đáp ứng một phần $44,4 \%$, bệnh giữ nguyên $11,1 \%$ và $13 \%$ bệnh tiến triển.

- Trung vị thời gian sống thêm không tiến 
triển 6 tháng (CI 95\%:5,5-6,5).

- Tiền sử trước đó chưa từng điều trị hóa chất liên quan đên tăng thời gian sống thêm bệnh không tiến triển (10 tháng so với 6 tháng, $\mathrm{p}=0,041)$.

\section{TÀl LIẸU THAM KHẢO}

1. Nguyễn Bá Đức (2007), Chẩn đoán và điều trị ung thư, NXB Y họ

2. Bùi Diệu, (2011), Một số bệnh ung thư phụ nữ, NXB Y hoc.

3. Đặng Tiến Giang và cộng sự (2020). Bước đầu đánh giá kết quả phác đồ lyposomal doxorubicin trên bệnh nhân ung thư nội mạc tử cung tái phát tại bệnh viện K. Tap chí y học Việt Nam, 497, 45-48.

4. Pectasides $D$, Xiros $N$, Papaxoinis $G$, et al. Carboplatin and paclitaxel in advanced or metastatic endometrial cancer. Gynecol Oncol.
2008;109(2):250-254. doi:10.1016/ j.ygyno.2008.01.028

5. Cohen CJ. Cytotoxic chemotherapy for patients with endometrial carcinoma. Clin Obstet Gynaecol. 1986;13(4):811-824

6. Miller DS, Filiaci VL, Mannel RS, et al. Carboplatin and Paclitaxel for Advanced Endometrial Cancer: Final Overall Survival and Adverse Event Analysis of a Phase III Trial (NRG Oncology/GOG0209). J Clin Oncol. 2020; 38(33):3841-3850. doi:10.1200/JCO.20.01076.

7. Trope CG, Alektiar KM, Sabbatini P, Zaino RJ. Corpus: epithelial tumors. In: Hoskins WJ, Perez CA, Young RC, Barakat RR, Markman M, Randall $M E$, eds. Principles and Practice of Gynecologic Oncology. $4^{\text {th }}$ ed. Philadelphia: Lippincott Williams and Wilkins;2005:823-872.

8. Huijgens ANJ, Mertens HJMM. Factors predicting recurrent endometrial cancer. Facts Views Vis Obgyn. 2013;5(3):179-186.

\section{MỐI TƯONG QUAN GIỮA NỒNG Độ HS-CRP VỚI MộT SỐ CHỈ SỐ XÉT NGHIỆM HÓA SINH LIÊN QUAN TRÊN BỆNH NHÂN ĐÁI THÁO ĐƯờNG TYP 2}

\section{TÓM TẮT}

Mở đâu: Tình trạng viêm kéo dài gây nên các biến chứng mach máu trong bênh đái tháo đường. Nếu không được kiểm soát và điều trị kịp thời bệnh nhân có thể tàn phế, tử vong. Xét nghiệm hs-CRP máu như một chỉ dấu sinh học hữu ích của tình trạng viêm mạch mạn tính, nhằm hố trợ chẩn đoán, theo dõi điều trị và phát hiện biến chứng một cách hiệu quả cho bệnh nhân đái tháo đường typ 2. Mục tiêu: Khảo sát mối liên quan giữa nồng độ hs-CRP máu với các chỉ số xét nghiệm hóa sinh (glucose máu đói, HbA1c, lipid máu) trển bệnh nhân đái tháo đường typ 2. Đối tượng: 238 người chia 2 nhóm: Nhóm bệnh gồm 118 bênh nhân đái tháo đường typ 2 và nhóm chứng gồm 120 người bình thường khỏe mạn, có độ tuổi và giới tính tương đương với nhóm bệnh. Phương pháp nghiên cứu: Nghiên cứu mô tả cắt ngang có đối chứng. Bệnh nhân được khám lâm sàng, khai thác tiền sử, bệnh sử, lấy máu tĩnh mạch lúc đói định lượng nồng độ hs-CRP, glucose, $\mathrm{HbA} 1 \mathrm{c}$, cholesterol toàn phần, LDL-C, HDL-C và triglyceride. Chẩn đoán đái tháo đường typ 2 theo tiêu chuẩn của ADA 2020. Kết quả: Nồng độ trung bình hs-CRP máu $(\mathrm{mg} / \mathrm{L})$ của nhóm bệnh và nhóm chứng lần lượt là $3,9 \pm 1,7$ so với $1,7 \pm 1,1 \mathrm{mg} / \mathrm{L}(\mathrm{p}<0.001)$. Sự khác biệt này có ý nghĩa thống kê. Bệnh nhân có nồng độ hs-CRP ở các mức độ nguy cơ cao và nguy cơ trung bình đối với

*Đai hoc Y Dước TP. Hồ Chí Minh

Chịu trách nhiệm chính: Lâm Vĩnh Niên

Email: nien@ump.edu.vn

Ngày nhận bài: 23.8.2021

Ngày phản biên khoa họ: 18.10.2021

Ngày duyệt bài: 28.10.2021

\section{Nguyễn Lê Hà Anh*, Nguyễn Thanh Trầm*, Vũ Trí Thanh*, Lâm Vĩnh Niên*}

bệnh tiểu đường typ 2 rất phổ biến (99,2\%). Trong đó, tỷ lệ phần trăm bệnh nhân ở các mức cao, trung bình và thấp lần lượt là 72,$9 ; 26,3$ và 0,8 . Nồng độ hsCRP máu tương quan thuận với glucose, HbA1c, cholesterol toàn phân, $L D L-C$ và triglyceride, tương quan nghịch với HDL-C. Kết luận: Nồng độ trung bình hs-CRP máu của người mắc đái tháo đường typ 2 cao hơn người không mắc đái tháo đường typ 2. Có mối tương quan thuận và có ý nghĩa thống kê giữa hsCRP với glucose, $\mathrm{HbA} 1 \mathrm{c}$, cholesterol toàn phần, $\mathrm{LDL}-\mathrm{C}$ và triglyceride, tương quan nghịch với $\mathrm{HDL}-\mathrm{C}$.

Từ khóa: hs-CRP, đái tháo đường typ 2.

\section{SUMMARY}

\section{CORRELATION BETWEEN HIGH-SENSITIVITY C- REACTIVE PROTEINS LEVELS (hS-CRP) AND SOME BIOCHEMICAL TEST INDEX IN TYPE 2} DIABETES PATIENTS

Background: Prolonged in inflammation causes vascularcomplications in diabetes. If not controlled and treated promptly, the patient can become disabled and die. Blood hs-CRP test as a useful biomarker of chronic vasculitis, in order to support diagnosis, monitor treatment and detect complications effectively for patients with type 2 diabetes. Aim: To examine the correlation between blood hs-CRP levels and some biochemical test index (glucose, HbA1c, total cholesterol, LDL-C, HDL-C and triglyceride) in type 2 diabetes patient. Sample: 238 pepple divided into two groups: group of 118 patients with type 2 diabetes and group of 220 healthy people (control group) having age and gender equivalent to the patient group. Method: A cross-sectional descriptive study. Patients under clinical examination, history abstraction, intravenous blood werw measured levels 